\title{
How prevalent is cancer family syndrome?
}

\author{
F Kee, B J Collins
}

\begin{abstract}
Based on an established but pragmatic definition of cancer family syndrome as the presence of three or more relatives affected by colorectal cancer in a first degree kinship, the contribution of this syndrome to the total cancer burden in Northern Ireland has been studied by investigating all non-polyposis probands under 55 years old at histological diagnosis between 1976 and 1978. Family interviews were possible for $95 \%(n=205)$ of all nonpolyposis probands and verification of vital status or medical history was obtained for $98 \%$ of 1811 first degree relatives. The prevalence of cancer family syndrome was between 1 and $2 \%$, a figure some fivefold less than that estimated elsewhere. A proximal tumour excess was not characteristic of the ascertained families. These results may have implications for the identification of susceptible people if screening for high risk groups is considered a worthwhile option for reducing colorectal cancer mortality in the United Kingdom.
\end{abstract}

To date, efforts to reduce mortality from colorectal cancer through mass screening have had limited success and despite the recruitment of over 250000 participants in five large controlled trials, a mortality reduction in the groups assigned to screening has yet to be shown.' Doubt has also been expressed about the value of sigmoidoscopic surveillance for polyps in asymptomatic average risk patients. ${ }^{2}$ A targeted approach, on the other hand, might increase the yield and cost effectiveness of screening threefold $^{3}$ if directed towards the $15 \%$ of patients with discernible risk factors. ${ }^{4}$ It has been suggested that cancer family syndrome (or hereditary non-polyposis colorectal cancer) overshadows all other predisposing conditions and constitutes the majority of this group for whom earlier diagnosis through screening is thought possible. ${ }^{5}$

Cancer family syndrome, a putatively autosomal dominant condition well reviewed by Lynch, ${ }^{6}$ is characterised in most reports by an early age of onset (40-45 years), a proximal tumour excess, a high risk of metachronous disease, and an excess of other adenocarcinomas in the kinship. There have, however, been relatively few attempts to determine the prevalence and features of this condition in defined populations, ${ }^{7-9}$ and its frequency in the United Kingdom has not previously been reported. The lack of a useful biomarker for the condition has hindered its documentation in both family studies and in population surveys and consequently, for the purposes of epidemiological comparison, the syndrome has had to be defined pragmatically. ${ }^{10}$
Nevertheless, the population context is preeminent among the factors that will determine the predictive utility of any biomarker." Thus more population based studies of the epidemiology of this condition are needed if the role of targeted screening for colorectal cancer is to be adequately assessed.

There are some advantages to studying this syndrome in Northern Ireland. The population is the most ethnically homogeneous in the United Kingdom, ${ }^{12}$ the mean family size is larger, and the proportion of illegitimate births is lower than in the rest of Britain. ${ }^{13}$ Also, the incidence and mortality from colorectal cancer in the province is the highest in the British Isles. ${ }^{1+15}$ We therefore report the first population based study of the prevalence and principal characteristics of cancer family syndrome in the United Kingdom.

\section{Patients and methods}

PATIENTS

All patients with colorectal cancer histologically diagnosed in Northern Ireland between 1976 and 1978 and under 55 years of age at the time of diagnosis were selected as probands. Hospital charts were reviewed and clinical details of age, sex, duration of symptoms, date of operation, family history, and tumour site and stage were extracted. The patient's current condition was initially established through the original general practitioner and hospital consultant, and for each deceased patient the death certificate was obtained.

\section{FAMILY ASCERTAINMENT}

With ethical committee approval, the surviving patient or the next of kin was contacted and a home interview conducted to establish the name, address, and vital status of each first degree relative. The master patient index of the central services agency (the local family practitioner committee) was used to trace the usual general practitioner of those relatives resident in Northern Ireland. Their general practitioners were informed of the purpose of the study and asked to provide details of any history of malignancy or bowel disease in their patient. A postal survey was conducted of the first degree relatives living outside Northern Ireland in which they were asked to give details of any personal medical history of malignancy, bowel disease or surgery. If such a history was obtained, the relevant hospital charts (or cancer registration particulars) were reviewed

Cause of death for each first degree relative was established according to the underlying rubric coded on the death certificate. 
Spectrum of major cancer types in 201 first degree relatives in: all families, families with two affected by colorectal cancer, and families with three or more affected by colorectal cancer

\begin{tabular}{|c|c|c|c|}
\hline Cancer type & $\begin{array}{l}\text { All families } \\
(n=205), \\
\text { relatives }=1811 \\
\text { Ist }(2 n d) \text { primary }\end{array}$ & $\begin{array}{l}\text { Families with } \\
2 \text { affected } \\
(n=40), \\
\text { relatives }=354 \\
\text { lst }(2 \text { nd }) \text { primary }\end{array}$ & $\begin{array}{l}\text { Families with } \\
3 \text { affected } \\
(n=13), \\
\text { relatives }=140 \\
\text { lst }(2 \text { d }) \text { primary }\end{array}$ \\
\hline Colorectum & *67 (2) & $40(0)$ & $27(2)$ \\
\hline Mouth/pharynx & $4(0)$ & $2(0)$ & $0(0)$ \\
\hline Oesophagus/stomach & $18(1)$ & $6(1)$ & $2(0)$ \\
\hline Small bowel & $1(0)$ & $1(0)$ & $0(0)$ \\
\hline Biliary tree & $3(0)$ & $1(0)$ & $0(0)$ \\
\hline Pancreas & $11(0)$ & $1(0)$ & $0(0)$ \\
\hline Larynx & $1(0)$ & $0(0)$ & $0(0)$ \\
\hline Lung & $27(2)$ & $8(0)$ & $2(1)$ \\
\hline Skin & $3(4)$ & $0(1)$ & $1(2)$ \\
\hline Breast & $11(1)$ & $2(1)$ & $1(0)$ \\
\hline Cervix/uterus & $19(0)$ & $4(0)$ & $1(0)$ \\
\hline Ovary & $2(0)$ & $0(0)$ & $0(0)$ \\
\hline Vagina & $2(0)$ & $0(0)$ & $0(0)$ \\
\hline Prostate & $3(1)$ & 0 (1) & $0(0)$ \\
\hline Bladder/kidney & $6(0)$ & $2(0)$ & $1(0)$ \\
\hline Secondary/unspecified & $7(0)$ & $1(0)$ & $0(0)$ \\
\hline Other & $16(0)$ & $2(0)$ & $0(0)$ \\
\hline
\end{tabular}

^One subject with an unverified cancer history has been omitted.

\section{ANALYSIS}

Following the practice adopted in previous reports on the frequency of this condition, ${ }^{7-9}$ kinships with three or more affected first degree relatives were taken to represent probable cases of cancer family syndrome. The clinical features of these cases were assessed with the $\chi^{2}$ test for contingency tables ${ }^{16}$ and the prevalence of the syndrome was calculated as a proportion of proband cancer burden.

\section{Results}

\section{ASCERTAINMENT}

During the three year study period there were 1241 cases of histologically diagnosed colorectal cancer in Northern Ireland (population 1.5 million) and of these, 222 were under 55 years at diagnosis. Five of the 222 were cases of polyposis coli and a further two patients were adopted. Of the 215 remaining probands, 10 families were uncooperative and the analysis below is restricted to the 205 cases $(95 \%)$ for whom a family interview was possible.

These 205 probands reported a total of 1811 first degree relatives, of whom $80 \%$ were resident in Northern Ireland. On the prevalence date (1 February, 1989), 569 of these relatives were dead. Excluding eight individuals killed in action during the Second World War, a death certificate was obtained for $98 \%$ of the remainder. For the 1242 living relatives, the vital status/medical history was secondarily verified in $98 \%$ of cases.

In all, 210 first degree relatives were reported by their family to have suffered cancer (of any site), and this was verified in 201 cases (96\%), of whom 160 were deceased. The types of cancer verified in these relatives are shown in the Table. Sixty eight first degree relatives of the 205 probands were reported to have had bowel cancer. For only one of these was no verification obtained, but of the remaining, the diagnosis was validated histologically in $32(47 \%)$, from a hospital chart in $12(18 \%)$, and from the death certificate alone in 23 cases (34\%).

Columns two and three of the Table indicate the apparent coaggregation of other cancers in families with two members affected by bowel cancer - that is, the proband plus one other - and in families with at least three affected by colorectal cancer.

\section{PREVALENCE}

There were only 13 families with three or more members affected by colorectal cancer (including the proband). The contribution to the total proband burden is thus 13 of 205 or $6 \%(95 \%$ confidence intervals $9 \cdot 7 \%-2 \cdot 9 \%$ ). However, of the 1241 cases diagnosed (at all ages) in the study period, the proband contribution is only $1 \%$.

Mecklin's estimate of prevalence also included some families with only two members affected by bowel cancer in the first degree kinship but with others affected by carcinomas supposedly typical of the cancer family syndrome - for example, cancer of the uterus, breast, or stomach. ${ }^{7}$ We judged that a further 10 families might thus be added to the prevalence calculation $(13+10)$ yielding a minimum estimate of 23 of 1241 or $1 \cdot 8 \%(95 \%$ confidence interval, $1 \%-2 \cdot 6 \%)$. This figure may be a reasonable approximation for the prevalence of the condition providing very few true cancer families have been missed by restricting the pedigree ascertainment to probands under 55 years.

In these 23 families there were 60 individuals affected by bowel cancer with a mean age at onset of 50.7 years (range 26-88 years). The site distribution of all bowel cancers arising in these patients is displayed in the Figure with the data from Lynch $^{17}$ and Mecklin ${ }^{18}$ shown for comparison. The proportion of cases with disease proximal to the splenic flexure in this study is $31 \%$, which is no different to the equivalent proportion (25\%) among all histologically diagnosed cases in the province in $1976-8\left(\chi^{2}=2 \cdot 3\right.$, df degree of freedom (1).

\section{Discussion}

This study has given a minimal estimate of the prevalence of the cancer family syndrome in Northern Ireland of between 1 and 2\%, a figure some fivefold less than estimated elsewhere by Lynch $^{6}$ and Mecklin. ${ }^{7}$ The possible reasons for the disparity include the following:

(1) An underestimate of the prevalence in Northern Ireland or an overestimate elsewhere;

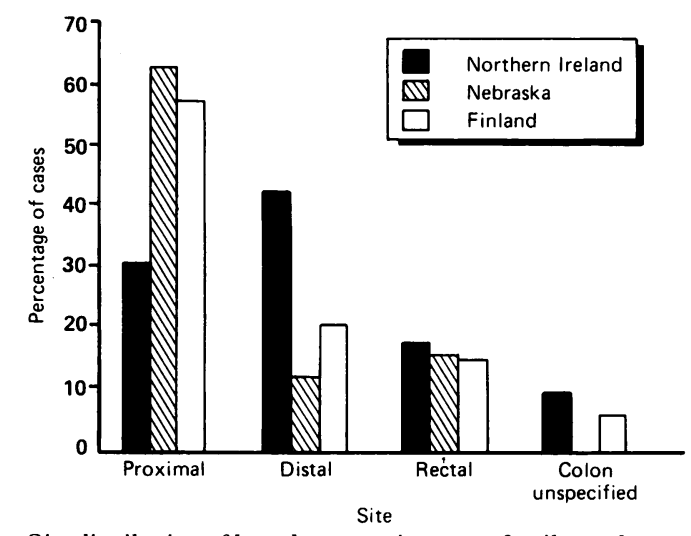

Site distribution of bowel tumours in cancer family syndrome families in selected studies. 
(2) Variation in the population characteristics which influence the expression of genetic susceptibility;

(3) A true difference in the incidence and prevalence of cancer family syndrome;

(4) Genuine genetic heterogeneity of the cancer family syndrome across different communities, or

(5) A combination of any of these.

It is obvious that information about the extended family, including previous generation second and third degree relatives, might give greater support to a genetic explanation for these familial clusters, but both the data quality and the ability to account for secular changes in exogenous risk factors would be less assured. In the Finnish study, death certificates were recovered for $85 \%$ of the parents of index cases and in the families offered screening $42 \%$ of first degree relatives either could not be traced or did not reply. ${ }^{719}$ In the Italian study, data on first degree relatives was validated for. $24 \%$ of the sample, ${ }^{8}$ and in the Australian study only 'where possible'. 9 Families were identified in all these studies on the pragmatic basis of three or more affected in a first degree kinship and it seems unlikely that the prevalence in Northern Ireland has been underestimated because of incomplete data validation.

Mecklin investigated all subjects with a diagnosis of colorectal cancer under the age of $70 .^{7}$ Only $10 \%$ of his cancer family syndrome probands were over 50 years of age and less than 1\% were over 60 . We may, however, have underestimated prevalence in Northern Ireland if significant clustering were present in families of cases aged over 55 years at diagnosis. It is possible that some environmental factor could reduce the penetrance of an obligate gene carrier, accounting for different ages at onset in different communities. ${ }^{20}$

It is recognised that a knowledge of the family history can affect the diagnostic process, ${ }^{22} 23$ and the age at diagnosis can be an artefact of the method of ascertainment, especially if surveillance is instigated in relatives of a young proband. ${ }^{6}$ This would obviously also have a bearing on the reliance that could be placed on the estimates of gene frequency derived from more complex segregation analysis. Even though the general transmission probability model can 'allow for the environmental determination' of the age at onset of cancer, ${ }^{2+}$ the carcinogenic milieu within the bowel lumen may itself be genetically determined through polymorphisms at other loci. ${ }^{25} 26$

Clearly, there may be a number of reasons why a pragmatic syndrome definition need not, as Lynch has intimated, provide frequency estimates that will be broadly comparable across communities. ${ }^{27}$ The results of even a complex segregation analysis will not be widely applicable if competing causes of death, which vary significantly in different populations, are not randomly distributed among affected and unaffected subjects. That this is a possibility was recently suggested by the significant deficit of ischaemic heart disease among cases in the Melbourne case control study. ${ }^{28}$

There are also grounds to dispute Mecklin's contention that 'there is no evidence that the proportion of hereditary cases is dependent on the overall incidence of cancer'? ${ }^{\text {? }}$ From first principles, it could be argued that in populations where the incidence is high - for example, in Northern Ireland - the proportion of disease attributable to susceptible subjects is expected to be lower than in populations where the incidence is relatively low, such as in Finland. ${ }^{29}$

In marked contrast to most other studies, there is no excess of proximal tumours among the cases identified in this Northern Ireland sample, despite the similarity in the methods of family ascertainment. It must be remembered that young cases are nearly always investigated and treated aggressively, whereas the elderly (who usually constitute the majority of population cases) are less likely to have their proximal tumours diagnosed during life. ${ }^{30}$ To compound this detection bias, the changing site distribution of colorectal tumours in the last 30 years may suggest that cohorts of different age have been subject to different environmental factors influencing site predilection. ${ }^{31}$ Although it is improbable that accounting for such potential biases could explain away the apparent proximal predominance of most descriptions of cancer family syndrome, our results agree with a recent population based study of familial colorectal cancer in Utah, in which a proximal predilection was not a characteristic of familial cases. ${ }^{32}$ The authors concluded that most of the published accounts of high risk families could not fully discount ascertainment bias in determining the clinical features of cases within a pedigree, and that even when consonant with a pattern of autosomal dominant inheritance, it is unlikely that a single hypothesised gene is responsible for all significant colorectal cancer clusters in the population. ${ }^{32}$

Undoubtedly the issue of genetic heterogeneity in cancer family syndrome will ultimately have to be resolved in the laboratory, but the predictive utility of any putative biomarker is unlikely to be assured unless the population context of ascertained families and their clinical features is adequately described. ${ }^{11}$ Although this is one of the largest and most highly verified family studies of its kind, there is an obvious need for more population based research if the potential for a more successfully targeted screening programme is ever to be realised.

The authors gratefully acknowledge that the funding for this study was provided by the Ulster Cancer Foundation.

1 Hardcastle JD, Pye G. Screening for colorectal cancer: a critical review. World f Surg 1989; 13: 235-45.

2 Frank JW. Causation revisited. F Clin Epidemiol 1988; 41 425-6.

3 Eddy DM. Computer models for surveillance of gastrointestinal disorders. In: Rozen P, de Dombal FT (eds). Computor aids in gastroenterology. Basel; $S$ Karger, 1984: 119-33.

4 DeCosse JJ. Early cancer detection. Cancer 1988; 62 (suppl): 1787-90.

5 Jarvinen $\mathrm{HJ}$. Premalignant conditions of the gastrointestinal tract: a selective basis for screening programs. Ann Med tract: a selective

6 Lynch HT, Lanspa SJ, Lynch JF. Hereditary colon cancer syndromes: polyposis and non-polyposis variants. In: Mac Donald J (ed). Gastrointestinal oncology: basic and clinical aspects. Boston, Martinus Nijhoff, 1987.

7 Mecklin JP. Frequency of hereditary colorectal carcinoma. Gastroenterol 1987; 56: 1021-5.

8 Ponz de Leon M, Sasseteli R, Sachetti C, et al. Familia aggregations of tumours in the three year experience of population based colorectal cancer registry. Cancer Res 1989; 49: 4344-48. 
9 Fisher G, Armstrong B. Familial colorectal cancer and the screening of family members. Med $\mathcal{F}$ Aust $1989 ; 150: 22-5$.

10 Lynch HT. Frequency of hereditary non-polyposis colorectal carcinoma. Gastroenterol 1986; 90: 486-96.

11 Schulte PA. Methodological issues in the use of biological markers in epidemiological research. Am F Epidemiol 1987 $126(6): 1006-16$.

12 Demographic trends in Northern Ireland. 1986. Belfast, Northern Ireland Economic Council Report 57

13 Continuous household survey. Department of Finance and Personnel. Northern Ireland Office. PPRU Monitor No (1) 1988

14 Kee F, Collins B, Patterson CC. A profitless parsimony? Ir F Med Sci 1990; 159 (2): 58

15 Office of Population Censuses and Surveys. Mortality Series DH1. (16); London OPCS, 1984.

16 Armitage P, Berry G. Statistical methods in medical research (2nd ed). Oxford, Blackwell, 1987.

17 Albano W, Recerbaren J, Lynch HT. Natural history of hereditary cancer of the breast and colon. Cancer 1982; 50 $360-3$

18 Mecklin J-P, Jarvinen H-J. Clinical features of colorectal carcinoma in cancer family syndrome. Dis Colon Rectum 1986; 29: 160-4.

19 Mecklin J-P, Jarvinen HJ, Aukee S, Elomaa I. Screening for colorectal carcinoma in cancer family syndrome kindreds. Scand f Gastroenterol 1987; 22: 449-53.

20 Greenwald P, Witkin KM. Familial adenomatous polyposis: a nutritional interventional trial. $7 N C I$ 1989; 81: 1272-3.

21 Graf E, Eaton JW. Dietary suppression of colonic cancer. Cancer 1985; 56: 717-8.

22 MacArthur C, Smith A. Factors associated with speed of diagnosis, referral and treatment in colorectal cancer. 7 Epidemiol Community Health 1984; 38: 122-6.

23 Farrands PA, Hardcastle JD, Chamberlain J, Moss S. Factors affecting compliance with screening for colorectal cancer. Community Med 1984; 6: 12-9.

24 Bailey-Wilson J, Elston RC, Schuelke GS, et al. Segregation analysis of hereditary nonpolyposis colorectal cancer. Gene Epidemiol 1986; 3: 27-38.

25 Spigelman AD, Phillips RKS. Genes and carcinogens. Lance 1989; ii: 1210

26 Stroebel HW, Hammond DK, White TB. Colonic microsomal enzymes and their role in colorectal carcinogenesis. In: Seitz HK, Simowski UA, Wright NA. (eds). Colorectal cancer: from pathogenesis to prevention. Heidelberg, Springer Verlag, 1989

27 Lynch HT. Frequency of hereditary non-polyposis colorecta cancer. Gastroenterol 1986; 90: 486-96.

28 Kune G, Kune S, Watson LF. Colorectal cancer risk, chronic illnesses, operations, and medications: Case-control results from the Melbourne colorectal cancer study. Cancer Res 1988; 48: 4399-404.

29 Khoury MJ, Flanders D, Greenland S, Adams MJ. On the measurement of susceptibility in epidemiologic studies. Am J Epidemiol 1989; 129: 183-90.

30 Delendi M, Gardiman D, Riboli E, Sasco A. Latent colorecta cancer found at necropsy. Lancet 1989; ii: 1331-2.

31 Gerharz CD, Gabbert H, Krummel F. Age dependent shift to . Virchows Arch 1987; 411: 591-8.

32 Cannon-Albright L, Thomas TC, Bishop T, Skolnick MH Burt R. Characteristics of familial colon cancer in a large population database. Cancer 1989; 64: 1971-5. 